\title{
Methodical Problems in Cross Cultural Studies: Equivalence-An Overview
}

\author{
Petia Genkova \\ University of Applied Science, Osnabrueck, Germany
}

\begin{abstract}
The following article deals with equivalence as a specific quality criterion concerning cross cultural research in psychology and provides an overview for this topic. The comparability of constructs as well as of data is analyzed. For this, the different levels of equivalence are regarded, e.g., translation equivalence and others. Classical as well as modern methods for the testing and guarantee of equivalence are analyzed. Critical approaches and methodical problems of cross cultural research are described.
\end{abstract}

Keywords: cross cultural psychology, equivalence, methodical problems, quality criterions of cross cultural research

\section{Introduction}

Cross-cultural research has become very important in our world where many people have been made vulnerable by others in more powerful positions (Liamputtong, 2010). Therefore, it is of great importance to protect cultural comparison studies methodically. In the present article, specific problems of cross cultural psychology are to be considered. The objective of this article is to briefly display the complexity of problems to demonstrate several possible solutions in empirical studies. Therefore, the demonstration is only schematic and not complete as methods such as experiments or tests were used in this paper.

A methodical difficulty in cultural comparison research is the fact that research lacks in fundamental papers that show how to empirically ensure and check comparability. These cross cultural psychology specific questions are also objects of the present article.

To what extent are patterns of response consistent? Is comparability ensured? Is actually the same phenomenon studied? How can negative connotations be avoided? Can these problems be solved statistically? Also an attempt is made to give precise recommendations how to deal with different methods in cultural comparison.

It is often emphasized that most of psychological questions are defined by their content and theories. In contrast cross cultural psychology is defined by its methods (Berry, 1980; Berry et al., 2012; Brislin, Lonner, \& Thorndike, 1973; Triandis \& Brislin, 1984; Lonner \& Berry, 1986). Comparative methods consequently form the central focuses of this discipline.

The cross cultural psychology attempts to compare and to search systematic covariance how cultural and behavioral variables are connected. All this is predestined to ascertain and to understand how two systems work,

Petia Genkova, Professor, Chair in Business Psychology, University of Applied Science. 
at the level of group analyses and individual analyses as well as in matters of the relation between both levels (Berry, 1980).

Consequently we come upon an important problem, namely the equivalence. We can compare phenomena if we identify a dimension, determine an equivalence and see universal relations. To this also belongs the great spectrum of phenomenon variations. The difficulty with this behavior lies in the level of analyses. At one level structures and functions are detected and on the other level phenomena are examined which hold a great variation of characteristics.

There are two ways of determining dimensional equivalence - by adaption of universals from the biology, linguistic, and anthropology respectively sociology or by empirical demonstration of the data's equivalence that are collected in both samples (Berry, 1980; Berry et al., 2012; Segall, Dasen, Berry, \& Poortinga, 1999; Shiraev \& Levy, 2000).

To the universals that are involved do not only belong the biological universals (biological needs) but also the universal phenomena from the anthropology (language, myths, etc.). Furthermore, phenomena from the sociology are included (a set of functional attributes of the social life, as differentiation of roles and normative regulation of behavior and socialization) (Berry, 1980).

As the cross cultural psychology concerns population and individual, it is related to several disciplines that are affected by characterizing and analyzing of human groups. At the individual level, the cross cultural psychology includes all fields of scientific resource, cocerning development, personality, cognition, perception and social behavior (Segall et al., 1999). Some disciplines at the population-level rather tend to naturalistic observation (e.g., ethnographical anthropology) or to questionnaires and scales, as they are favored by the psychology for empirical research. Anthropology is most closely related to the cross cultural psychology (Segall et al., 1999; Greenfield, 1997; Poortinga, 1997). Theories and concepts of society are not always applicable to another one. The fundamental paradox and dilemma of cultural comparison research is measuring and observation of behavior in different cultures sometimes without knowing what is actually observed and measured. To solve this especially non-western researchers go the way of the indigenous psychology (Segall et al., 1999; Berry et al., 2012).

But still the basic problems of the empirical psychological research, concerning the quality criteria objectivity, reliability and validity, come along.

\section{Equivalence and Comparability}

The difficulty with equivalence is one of the most important points of methodical problems in cross cultural psychology. As the cultural context is often considered as manipulative variable (Smith \& Bond, 1998), standardization of procedure within the subjects is very difficult (Bond, 1988). Usually response-sets are developed for this (Hui \& Triandis, 1989) and serve as generalized conventions or moderation tendencies. Indeed this creates an interaction with the context, but the interaction is not comparable between the cultures.

By elimination of the scale's mean ranks the tendency to use scales in different ways in different cultures can be reduced. Culture's individual research traditions relating to dealing with anonymity are of equal importance. No valid data will be received if there are fears relating to the handling of the collected data.

Berry et al. (2012) suggest three kinds of equivalence that need to be considered in the cross cultural Psychology: functional, conceptual, and metrical equivalence. 
The functional (also called operational) equivalence exists if two or more behaviors (in two or more cultural systems) are connected with common functional problems. The question here is whether the collected data are indicators for the same underlying processes or attributes. Is the functional equivalence possible? Beside the demographical differences, also different linguistic connotations and conceptions play a role. Moreover (Jahoda, 1979; Smith \& Bond, 1998), cultural differences actually belong to the subjects of social psychology (Van de Vijver \& Leung, 1997; Smith \& Bond, 1998; Berry et al., 2012; Segall et al., 1999) and theories that were especially developed for the cross cultural psychology are missing.

The conceptual equivalence applies to that the meaning of research materials (stimuli, concepts, etc.) or behavior are equivalent, even before a comparison is possible (Sears, 1961). The basic question asked here: Are "content" and the meaning of the researched construct identic? In this context, the researcher is looking for the local cognitive conceptions and concepts concerning a specific phenomenon. If common conceptions are found, a comparison is legitimate. In contrast to the functional equivalence, the conceptual equivalence is a requirement for this comparison. The conceptual equivalence is characterized by its universality and specific (Warwick \& Osherson, 1973). Additionally, comparability and identification, as important problems of cultural comparisons, are related to it. Although some concepts are universal for some cultures, they are specific for other cultures. The definition of variables with common connotations is very difficult. Even the definition of categories such as socio-economic status, abnormality, etc., is difficult in different cultures (Pareek \& Rao, 1980). Przeworski and Teune (1970) suggest a way how to solve the problem of equivalence in culture comparisons: (1) Indicators of similar variables are represented in different ways in different populations; and (2) The influence of a third, intervening variable can be included in cultural comparison's analysis.

Linguistic equivalence is understood to mean the translation problems (Deutscher, 1973; Anderson, 1973). The linguistic equivalence will be discussed and clarified in contrast to the functional and conceptual equivalence.

Several methods tried to involve and transfer these aspects. One of these is the direct retranslation of words, sentences and items into the original language. This technic is used to demonstrate the translation equivalence (Brislin, 1970; 1986) and involves a bilingual person that executes the translation in one direction. The retranslation into the original will be executed by someone else. Discrepancies between both variations often represent an indicator for lacking conceptual equivalence. Variations of this technic were developed by Brislin, Lonner, and Thorndike (1973).

Another approach for the conceptual equivalence represents the semantic differential (Osgood, 1964).

It should further be kept in mind that the ethnologic and cognitive tradition of anthropology prove that phenomena or experiences are classified in different ways and into different cultural groups. This kind of analysis pursues the objective to determine by the analysis of linguistic structures and object-classifications how the environment in cognitive structures of humans are organized. There will be no conceptual equivalence if the structures of concepts are different.

Metric equivalence is deemed to occur if the metric attributes of two (or more) data sets of two (or more) cultural groups possess the same factual coherence in structures. This also includes the scale-equivalence and the ascertainment-equivalence (Do every individuals have equal chances to get to similar answers and solutions?).

Measuring-equivalence is understood to mean the testability, comparability of contexts, comparability of answers and comparability of reliability and validity. 
The problem of measuring-equivalence is particularly discussed in developmental psychology and cross cultural psychology (Van de Vijver \& Poortinga, 1997). The question here is whether instruments that were constructed for different age groups and to measure the same psychological variables fulfil their purpose or not. Concepts of test-fairness and culture-fairness are closely related to concepts of measuring-equivalence (Cleary, 1968; Jensen, 1980). A test is classified as unfair if in different cultures it is not equal in difficulty, selectivity and validity due to diagnostically irrelevant factors (e.g., familiarity with test tasks) and test-based diagnostic decisions (e.g., university degree) lead to disadvantages of certain groups (Wottawa \& Amelang, 1980; Schmitt, Maes, \& Seiler, 2001). Frequently, tests are also applied to the same language since even the fluent usage of a foreign language is ethnocentrically referred to as a lack of linguistic abilities due to accent or minor mistakes.

The equivalence question may prove difficult in particular since it demands knowledge that is generated by instruments of questionable equivalence. Also the culture-fairness of a measuring instrument can only be assessed once the real cultural difference is known. However, the cultural difference can only be empirically determined by those instruments with substantiated culture-fairness.

Finally, the question whether an apparent gap in performance between groups represents a fairness problem can only be answered when knowledge of the true performance capability is available, which determination requires fair tests. Also the availability of a validation criterion (e.g., professional success as criterion of aptitude tests) does not principally solve the problem since the criterion itself may be unfair (Darlington, 1971; Schmitt et al., 2001). Due to the limited amount of space available, metric equivalence is not mentioned any further.

In the following, the problem of translation equivalence is discussed as a possible solution approach.

\section{Equivalence in the Translation}

As translation is important in quantitative empiric analyses, it will be considered in more detail. Smith and Bond (1998) name comparability and linguistic differences as main problems of cultural comparison research (Segall et al., 1999; Berry et al., 2012; Berry et al., 1997; Triandis, 1980).

A scientific consideration of a phenomenon must always consider the cultural context as well. This also applies to comparison of two groups and the translation equivalence.

Brislin et al. (1973) are concerned with the translation issue. In this context, their research activities are one of the most cited works. The language plays an important role in intercultural communication. This issue was questioned and improved in most concepts for intercultural trainings (Beatty, 2001). In the 1980s, a boom of intercultural trainings emerged that gave the impetus for the empirical cultural comparison research.

Brislin (1980) considers all important aspects of this process. Irrespective of what method we use, we must deal with the translation equivalence. He lists the following aspects that must be considered in doing so: codification, reliability, validity; translation (context and redundancy); previous ethnological studies — under it folklore and ethnological descriptions - which findings should be considered; the way how one construct is differently defined in cultures (e.g., In-/Outgroup are differently defined in the USA/Greece; Triandis et al., 1968); Etic-Emic-approach, to what extent items are suitable or not suitable for comparison.

To reach the translation equivalence the content analysis is used. By the content analysis sources (e.g., of verbal, written, visual and communicative kind, physical movements) in different cultures are systematically studied to make important generalizations about human behavior. The content analysis features objectivity, that is to say the categories are formed by the content and are descriptive and not characterized by formalized hypotheses and generation of theoretical relevance. 
In this context, it points out four important aspects: (1) collecting of materials; (2) development of criteria respectively categories and encoding of materials, also by interval scales "Disagree" (1) — "Agree" (7); (3) reliability of the encoding procedure; and (4) determination of the validity for the results. These aspects are thoroughly interpreted. The content analysis' strengths are simultaneously its weaknesses.

Validity is achieved by comparison with independent criteria, application of multiple methods and construct validity (Cronbach \& Meehl, 1955; Cronbach, 1975).

The content analysis is of great importance for the cross cultural psychology, as it gives good ideas for theoretical conceptualization and generation of hypotheses and includes the Antezendent-Konsequent-method (Triandis, 1972) and modes of narration (Brislin, 1980).

Furthermore, the formal methods are included in the content analysis. Therefore, in case of the ethnology, fasset-analyses and general-class analyses are used.

By translation of material in different languages we face great difficulties. In the following different kinds of translations are differentiated: pragmatic translation, aesthetic-poetic translation, ethnographic translaton and linguistic translation.

For translation, e.g., of a questionnaire, the importance of context and redundancy is to be emphasized. Redundancy helps to construct materials; by them we assure that information is perceived correctly (Brislin, 1980). On the one hand, unfortunately, test subjects often give negative feedback when redundancy is strong. On the other hand, when test subjects perceive it in this way, it implies that the meaning is not missed. Additionally, the context is important since every word is part of a sentence and sentences are combined to paragraphs (Brislin, 1980). Three rules for translation are suggested: Firstly, the use of vocabulary that is as simple as possible and comprehensible for all included people. Second rule is the mainly use of familiar words.

In the cross cultural psychology, the following translation methods have established themselves to assure reliability, validity and equivalence. It is to emphasize that these methods were developed by Brislin during his research work and he is deemed to be the most important author in this subject, which is why he is cited and why his methods are used in the most works of the cross cultural psychology. The translation method by Brislin (here 1980) are: Back Translation, bilingual technic (this technic is also known as split-half-reliability), committee-approach (a group of bilingual persons translate the questionnaire into the target language) and Pretest-Procedures (after the translation all methods are to be tested in the field (Brislin et al., 1973; Pareek \& Rao, 1980)).

In the analyses of equivalence, also the stimulus' context should be analyzed. First stage of the equivalence analyses is to pay attention to the content of stimuli or items in an instrument (Berry et al., 2012). The expert evaluation method and methods for translation equivalence are used for this. In the expert evaluation method, experts are asked to give their opinions about the content of stimuli. This method is often practiced in the USA. However, it is difficult to always find suitable experts.

Van de Vijver and Poortinga (1991) provide a good overview of this procedure's methodical specifics. It is important to identify the connection of the items within the instrument (structural aspects) (Van de Vijver \& Leung, 1997).

Tilov et al. (2012) found that in general the cross-cultural adaptation process does not always lead to the best target version and suggests, it would be useful to develop new scales specific to each culture and to think about the trans-cultural adaptation. 
Based on the research of Cheung (2012) in cross-cultural personality assessment, the author described the inadequacies of sole reliance on either the etic or the emic approach and points out the advantages of a combined emic-etic approach in bridging global and local human experiences in psychological science and practice. She said that there are parallel needs of acknowledging universals and specifics when mainstreaming culture in psychology.

\section{Discussions and Critical Approaches in Cross Cultural Psychology}

To present a well elaborated study in cultural comparison, not only ethic problems of data collection it should be considered but also specific cases of self-ethnocentric or ego-centric perception and patterns of thinking should be prevented. In this connection, one speaks of critical approaches in cross cultural psychology (Shiraev \& Levy, 2000).

In the specialist literature, there is no consensus about the question whether an Etic- or Emic-analysis or both should be used. Though, for quite some time, the inclusion of descriptions of researched culture models and a culture-specific analysis is not only noticed as pleasant for the reader but also as very useful. However, this is strongly criticized by empiricists when it is not based on empirical data. Often the reader also has no detailed idea of the displayed concepts and then such short descriptions of cultural models concerning the studied phenomenon play the role of an "Informant" about the presented results. In addition, it makes certain results more comprehensible and provides explanations. However, data or public reports shall rather be used as sources, if possible. The explicit and exact differentiation between subjective experience, individual cases and determined pattern is to be conducted. Psychology is an empirical science and in its cultural-comparative approach is strongly criticized by humanities as ethnology, anthropology, etc., and also by natural sciences due to simplification and shallowness. Such additional declarations will not endanger the empirical approach since only empirically detected results are crucial for the analysis. The last-mentioned are often ignored, even though the changes and current status, respectively the phenomenon's characteristic in context of an empirical science should be emphasized and stated. Also non-significant results should be considered, as they also have informative value - just as in the natural sciences. Replication of constant, non-significant results in the cross cultural psychology shall be noted to work against subjective theories and to facilitate intercultural communication as a practice-relevant aspect. Despite personal doubts of the scientist, particular attention should be paid to the contra-intuitive results, since those can be used as good predictors. Examples are cognitive dissonance (e.g., importance of participation in the experiment under poor payment in comparison to unimportance under good payment) and the fact that realistic persons tend to depressive moods.

By this differentiation of studies and the analysis of methodical difficulties, Van de Vjiver and Leung (1997) formulated the following issues of the cross cultural psychology that should serve as guideline for cultural comparisons: Value differences in social and behavioral measurements between cultures can be interpreted differently. Therefore, in cultural comparison studies a suitable access to each group is necessary. Several methods should be used to increase the validity of cultural comparison and the transformation of the culture into a context variable is a methodically good solution to include interpretations of cultural differences and to reduce the number of alternative interpretations. The equivalence can not only be supposed but determined, even though higher levels of equivalence are more difficult to set. The interpretability of intercultural studies is to be optimized by combination of essential, methodical, and statistical considerations. 
However, the cultural comparison research is indispensable to determine the generalizability of theory and empirical results.

Finally, it shall be given an answer to the question why cultural comparison science is necessary: It increases the validity's variance of variables, helps to obtain completely different variables and makes them accessible, helps to reduce disturbance variables and to analyze the context in that the behavior is shown. The maximization of differences in persons' attributes is considered. To implement this methodically and ethnically correctly, in the cultural comparison research shall be still made a preferably theory-based selection of comparison-cultures. The translation of test materials should be carried out by "forward-backward-translation"-procedure. Parallelization of test persons according to relevant influence variables shall be conducted. Ensuring of functional similarity of experimental manipulations in both cultures is absolutely necessary, just as well as adaption of test format to the experience background of the participants. It is also important to ensure the elimination or comparability of disturbance variables. In matters of researches by questionnaire, answer formats, e.g., "Say-Yes-tendencies" are to be considered and controlled. Ensuring of same, internal structures of data in all comparison cultures shall be considered. At last the political conditions of the context should not be disregarded.

It can be largely discussed about the dependence of cultural comparison research from political orientation.

Furthermore, a problematic question is the ethnocentrisms, the desire to behave oneself judgmentally when presenting the results. Transparency and access to groups, organizations and information (e.g., in comparisons that were commissioned by the EU or UNO) are also often problematic. Frequently, compromises concerning the design, execution, and conceptualization are made to ensure comparability. Beyond that it is difficult to illustrate the interpretation in a scientifically correct way without touching problematic subjects.

It should not be forgotten that every research implicates a direct or indirect consequence for several members of a society and further research projects. This applies particularly to the cross cultural psychology in times of integration and globalization, this is frequently accused of enforcing limited or not widely spread patterns of the western world. Integration without harming the own identity or cultural specifics should be the task of cross cultural psychology.

\section{References}

Allik, J., Massoudi, K., Realo, A., \& Rossier, J. (2012). Personality and culture: Cross-cultural psychology at the next crossroads. Swiss Journal of Psychology, 71(1), 5-12.

Anderson, R. B. W. (1973). On the comparability of meaningful stimuli in cross-cultural research. In: D. P. Warwick, \& S. Osherson (Eds.), Comparative research methods (pp. 149-162). Englewood Cliffs, N.J.: Prentice-Hall.

Beatty, J. (2001) Language and communication. In: L. L. Adler, \& U. P. Gielen (Eds.), Cross-cultural topics in psychology (pp. 47-62). Westport, Connecticut: Praeger Publishers.

Berry, J. W. (1980). Ecological analyses for cross-cultural psychology. In N. Warren (Ed.), Studies in cross-cultural psychology (Vol. 2). London: Academic Press.

Berry, J. W. (1980). Introduction in methodology. In: H. C. Triandis, \& J. W. Berry (Eds.), Handbook of cross-cultural psychology: Methodology (Vol. 2, pp. 1-28). Boston: Allyn and Bacon.

Berry, J. W., Poortinga, Y. H., \& Pandey, J. (Eds.) (1997). Handbook of cross-cultural psychology (Vol. 1): Theory and method. Boston: Allyn and Bacon.

Berry, J. W., Poortinga, Y. H., Segall, M. H., \& Dasen, P. R. (2012). Cross-cultural psychology: Research and applications. Cambridge: Cambridge University Press.

Bond, M. H. (Ed.) (1988). The cross-cultural challenge to social psychology. Newbury Park: Sage Publications. 
Brislin, R. H. (1970). Back-translation for cross-cultural research. Journal of Cross-Cultural Psychology, 1, $185-216$.

Brislin, R. W., Lonner, W., \& Thorndike, R. M. (1973). Cross-cultural research methods. New York: John Wiley \& Sons.

Brislin, R. H. (1980). Translation and content analysis of oral and written material. In: H. C. Triandis, \& J. W. Berry (Eds.), Handbook of cross-cultural psychology: Methodology (Vol. 2). Boston: Allyn and Bacon.

Brislin, R. W. (1986). The wording and translation of research instruments. In: W. J. Lonner, \& J. W. Berry (Eds.), Field methods in cross-cultural research (pp. 137-164). Beverly Hills: Sage Publications.

Cheung, F. M. (2012). Mainstreaming culture in psychology. American Psychologist, 67(8), 721-730.

Cleary, T. A. (1968). Testbias: Prediction of grades of negro and white students in integrated colleges. Journal of Educational Measurement, 5, 115-124.

Cronbach, L. (1975). Beyond the two disciplines of scientific psychology. American Psychologist, 30, 116-127.

Cronbach, L., \& Meehl, P. (1955). Construct validation in psychological tests. Psychological Bulletin, 52, 281-302.

Darlington, R. B. (1971). Another look at "cultural fairness". Journal of Educational Measuremnt, 8, 71-82.

Deutscher, I. (1973). Asking questions cross-culturally: Some problems of linguistic comparability. In: D. P. Warwick, \& S. Osherson (Eds.), Comparative research methods (pp. 163-203). Englewood Cliffs, N.J.: Prentice-Hall.

Greenfield, P. M. (1997). Culture as process: Empirical methods for cultural psychology. In: J. W. Berry, Y. H. Poortinga, \& J. Pandey (Eds.), Handbook of cross-cultural psychology (Vol. 1): Theory and method. Boston.

Hambleton, R. K., Swaminathan, H., \& Rogers, H. J. (1991). Fundamentals of item response theory. Newbury Park, C.A.: Sage.

Holland, P. W., \& Wainer, H. (Eds.) (1993). Differential item functioning. Hillsdale, N.J.: Erlbaum.

Hui, C. H., \& Triandis, H. C. (1989). Effects of culture and response format on extreme response style. Journal of Cross-Cultural Psychology, 20, 296-309.

Jahoda, G. (1979). A cross-cultural perspective on experimental social psychology. Personality and Social Psychology Bulletin, 5 , 142-148.

Jensen, S. R. (1980). Bias in mental testing. London: Methuen.

Liamputtong, P. (2010). Cross-cultural research and qualitative inquiry. Turkish Online Journal of Quality Inquiry, 1(1), 16-29. Retrieved from http://www.tojqi.net/articles/TOJQI_1_1/TOJQI_1_1_Article_2.pdf

Lonner, W. J., \& Berry, J. W. (Eds.) (1986). Field methods in cross-cultural research. Beverly Hills: Sage Publications.

Mylonas, K. (2009). Statistical analysis techniques based on cross-cultural research methods: Cross-cultural paradigms and intra-country comparison. The Journal of the Hellenic Psychological Society, 16(2), 185-204.

Osgood, C. E. (1964). Semantic differential technique in the comparative study of cultures. American Anthropologist, 66, 171-200.

Pareek, U., \& Rao, T. V. (1980). Cross-cultural surveys and interviewing. In: H. C. Triandis, \& Berry (1980), Handbook of cross-cultural psychology Vol. 2: Methodology (pp. 127- 179). Allyn, and Bacon, Inc., Boston, London, Sydney, Toronto.

Poortinga, Y. H. (1997). Towards convergence? In: J. W. Berry, Y. H. Poortinga, \& J. Pandey (Eds.), Handbook of cross-cultural psychology (Vol. 1): Theory and method (347-388). Boston: Allyn and Bacon.

Przeworski, A., \& Teune, H. (1970). The logic of comparative social inquiry. New York: Wiley-Interscience.

Schmitt, M., Maes, J., \& Seiler, U. (2001). Zur Meßäquivalenz und strukturellen Invarianz von Indikatoren der seelischen Gesundheit bei Ost- und Westdeutschen. Zeitschrift für Differentielle und Diagnostische Psychologie, 21, 87-99.

Sears, R. R. (1961). Transcultural variables and conceptual equivalence (pp. 445-455). In B. Kaplan (Ed.), Studying personality cross-culturally. Evanston, I.L.: Row, Peterson and Co.

Segall, M. H., Dasen, P. R., Berry, J. W., \& Poortinga, Y. H. (1999). Human behavior in global perspective: An introduction to cross-cultural psychology. Boston: Allyn \& Bacon.

Shiraev, E. B., \& Levy, D. A. (2000). Introduction to cross-cultural psychology. Boston: Pearson.

Smith, P. B., \& Bond, M. H. (1993). Social psychology across cultures: Analysis and perspectives. Hemel Hempstead: Harvester Wheatsheaf.

Smith, P. B., \& Bond, M. H. (1998). Social psychology across cultures (2nd ed.). Hemel Hempstead: Harvester/Wheatsheaf.

Thorndike, E. L., \& Lorge, I. (1944). The teacher's word book of 30,000 words. New York: Teachers College, Columbia University.

Tilov, B., Dimitrova, D., Stoykova, M., Tornjova, B., Foreva, G., \& Stoyanov, D. (2012). Cross-cultural validation of the revised temperament and character inventory in the Bulgarian language. J. Eval Clin Pract, 18(6), 1180-1185.

Triandis, H. C., Vassiliou, V., \& Nassiakou, M. (1968). Three cross-cultural studies of subjective culture. Journal of Personality and Social Psychology Monograph Supplement, 8, 1-42. 
Triandis, H. C. (1972). The analysis of subjective culture. New York: John Wiley.

Triandis, H. C. (1976). Approaches toward minimizing translation (pp. 229-243). In: R. Breslin (Ed.), Translation: Applications and research. Wiley/Halstead; New York.

Triandis, H. C. (1980). Introduction to handbook of cross-cultural psychology. In: H. C. Triandis, \& W. W. Lambert (Eds.), Handbook of cross-cultural psychology-Perspectives (Vol. 1). Boston: Allyn and Bacon.

Triandis, H. C., \& Brislin, R. W. (1984). Cross-cultural psychology. American Psychologist, 39(9), 1006-1016.

Van Der Flier, H., Mellenbergh, G. J., Adèr, H. J., \& Wijn, M. (1984). An iterative item bias detection method. Journal of Educational Measurement, 21, 131-145.

Van de Vijver, F. J. R., \& Leung, K. (1997). Methods and data analysis for cross-cultural research. Newbury Park, C.A.: Sage.

Van de Vijver, F. J. R., \& Poortinga, Y. H. (1997). Towards an integrated analysis of bias in cross-cultural assessment. European Journal of Psychological Assessment, 13, 29-37.

Warwick, D. P., \& Osherson, S. (1973). Comparative research methods. Englewood Cliffs, N.J.: Prentice-Hall.

Wottawa, H., \& Amelang, M. (1980). Einige Probleme der "Testfairness" und ihre Implikationen für Hochschulzulassungsverfahren. DIAGNOSTICA, 26(3), 199-221. 